\title{
INFORMASI PERDAGANGAN AKAR KUNING DI PASAR TRADISIONAL MARTAPURA DAN PASAR TRADISIONAL RANTAU, KALIMANTAN SELATAN
}

\author{
Syamsu Eka Rinaldi*, Suryanto, Septina Asih Widuri \\ Balai Penelitian dan Pengembangan Teknologi Konservasi Sumber Daya Alam \\ Jl. Soekarno Hatta Km. 38 Samboja PO Box 578 Balikpapan76112; Telp. 0542-7217663 \\ *Corresponding email author: se.rinaldi@yahoo.com
}

\begin{abstract}
ABSTRAK
Akar kuning merupakan salah satu tumbuhan obat asli Kalimantan yang terdiri dari sedikitnya tiga spesies yaitu Fibraurea tinctoria Lour., Arcangelisia flava Merr. dan Coscinium fenestratum (Gaertn.) Colebr. Bagian batang dan akar dari tumbuhan ini dimanfaatkan secara tradisional oleh etnis asli Kalimantan seperti Dayak dan Banjar serta Kutai untuk mengobati beberapa penyakit seperti malaria, hepatitis/liver dan kencing manis. Khasiat tersebut didukung oleh berbagai penelitian yang menyebutkan akar kuning mengandung senyawa kimia yang berperan sebagai hepatoprotektor, antibakteri, anti malaria dan anti kanker. Jenis Coscinium fenestratum memiliki nilai komersial tinggi di India dan Srilangka sebagai bahan baku industri obat modern. Perdagangannya di negara tersebut telah diatur sangat ketat karena berimbas pada kelangkaan jenis tersebut akibat eksploitasi besar-besaran. Meskipun akar kuning memiliki potensi besar sebagai bahan baku industri obat modern, namun saat ini informasi perdagangan akar kuning di Indonesia masih sangat terbatas. Kajian ini dilakukan untuk mengumpulkan informasi perdagangan akar kuning di sejumlah pasar tradisional di Kalimantan Selatan. Informasi dasar ini diharapkan dapat menjadi pertimbangan dalam menentukan strategi pengembangan dan pemanfaatan akar kuning sebagai komoditas Hasil Hutan Bukan Kayu (HHBK). Berdasarkan pengumpulan data di lapangan, kebutuhan akar kuning untuk industri jamu tradisional di Kalimantan Selatan masih relatif sedikit. Ketersediaan akar kuning masih memadai dan belum terjadi eksploitasi besar-besaran di alam untuk pasokan akar kuning di wilayah Kalimantan Selatan.
\end{abstract}

Kata kunci: akar kuning, perdagangan, Kalimantan Selatan

Submitted on:4 April 2017

Accepted on: 9 November 2017

DOI: https://doi.org/10.25026/jsk.v1i8.58

\section{PENDAHULUAN}

Pemanfaatan tumbuhan obat tradisional untuk penyembuhan, merupakan bentuk pengobatan tertua di dunia. Hampir di setiap budaya di dunia dan di daerah Indonesia dijumpai tanaman yang dapat dimanfaatkan sebagai obat tradisional. Kandungan senyawa kimia yang beragam untuk obat tradisional dijumpai pada organ tubuh tumbuhan seperti daun, bunga, buah, biji, akar, rimpang dan kulit batang (Hornok. L, 1992)

Sejak ratusan tahun yang lalu masyarakat Indonesia memiliki tradisi memanfaatkan tumbuhan dari lingkungan sekitarnya sebagai obat tradisional.
Banyak etnis masyarakat Indonesia yang erat kehidupannya dengan alam dan memiliki pengetahuan tradisional yang tinggi dalam memanfaatkan tumbuhan obat. Berbagai penelitian etnofitomedikaetnobotani yang dilakukan oleh peneliti Indonesia telah diketahui, paling tidak ada 78 spesies tumbuhan obat yang digunakan oleh 34 etnis untuk mengobati penyakit malaria, 133 spesies tumbuhan obat yang digunakan oleh 30 etnis untuk mengobati penyakit demam, 110 spesies tumbuhan obat yang digunakan oleh 30 etnis untuk mengobati penyakit gangguan pencernaan dan 98 spesies tumbuhan obat digunakan untuk mengobati penyakit kulit oleh 27 etnis (Sangat et al., 1999) . 
Dari berbagai spesies tumbuhan obat tersebut diantaranya di Kalimantan tanaman obat tradisional yang telah dimanfaatkan salah satunya adalah akar kuning.

Tanaman akar kuning yang terdiri dari 3 spesies yaitu Fibraurea tinctoria Lour, Arcangelisia flava Merr dan Coscinium fenestratum (Gaertn.) Colebr. merupakan liana berkayu yang digunakan sebagai obat oleh masyarakat Suku Dayak, Banjar, maupun Kutai di Kalimantan. Tanaman ini dapat tumbuh di hutan dengan berbagai topografi dari lereng sampai dengan hutan rawa gambut. Manfaat akar kuning mulai dikenal khasiatnya karena mampu mengobati kerusakan hati, menambah daya tahan tubuh, dan anti diabetes karena mengandung senyawa berberin (Ahmed et al., 2015; El-Wahab et al., 2013; Raza et al., 2015; Sun et al., 2009). Di antara ketiga jenis akar kuning tersebut, jenis Coscinium fenestratum memiliki nilai komersial tinggi di India dan Srilangka sebagai bahan baku industri obat modern. Perdagangannya di negara tersebut diatur sangat ketat karena berimbas pada kelangkaan jenis Coscinium fenestratum akibat eksploitasi besar-besaran.

Meskipun saat ini akar kuning belum sepopuler pasak bumi, namun permintaan pasar akar kuning di Indonesia diperkirakan akan semakin meningkat seiring dengan timbulnya kesadaran masyarakat untuk kembali ke alam (back to nature ) dan mengkonsumsi obat alami. Menurut Indartik (2009), hal tersebut juga diperkuat dengan semakin meningkatnya jumlah industri jamu, farmasi dan kosmetik sehingga akar kuning sebagai salah satu komoditi biofarmaka di sektor kehutanan memiliki peluang untuk dikembangkan. Kanaya \& Firdaus (2009) menyatakan bahwa berdasarkan analisis keunggulan komparatif, Indonesia memiliki daya saing yang baik terhadap komoditas ekspor produk biofarmaka dibandingkan dengan negara pesaing.

Perdagangan dunia untuk produk tumbuhan obat (herbal) pada tahun 2000 sekitar US\$ 20 miliar dengan pasar terbesar adalah di Asia (39\%), diikuti dengan Eropa (34\%), Amerika Utara $(22 \%)$, dan belahan dunia lainnya $(5 \%)$ (Pramono E, 2002). Di tahun 2001 terjadi peningkatan penjualan menjadi US\$ 45 miliar (Biofarmaka-IPB, 2002).

$$
\text { Masalah utama dalam }
$$
pengembangan produk biofarmaka adalah produktivitas yang menurun dari sumber tumbuhan atau tanaman sebagai bahan utama dari produk biofarmaka. Untuk itu peluang pengembangan tersebut bergantung kepada besarnya permintaan akar kuning. Untuk mengetahui besarnya peluang pengembangan akar kuning tersebut, perlu diketahui bagaimana potensi pasar akar kuning. Potensi pasar merupakan salah satu cara yang dapat dijadikan sebagai parameter peluang. Tujuan dari penelitian ini adalah untuk memberikan informasi bagaimana potensi pasar akar kuning sebagai bahan baku obat tradisional khususnya di Kalimantan Selatan.

\section{METODE PENELITIAN}

\section{Lokasi Penelitian}

Penelitian ini dilaksanakan selama pada bulan Oktober 2016. Lokasi pengambilan data adalah di Pasar Martapura dan Pasar Rantau Provinsi Kalimantan Selatan. Pemilihan lokasi didasarkan pada kegiatan perdagangan akar kuning dan industri jamu tradisional yang mengolah akar kuning.

\section{Teknik Pengambilan Sampel}

Dalam penelitian ini yang menjadi obyek penelitian adalah pedagang obat 
tradisional baik itu berupa simplisia atau jamu. Pemilihan dan pengambilan contoh pelaku objek kajian dilakukan secara accidental random sampling, dengan mendatangi pedagang yang berada di Pasar Martapura dan Pasar Rantau.

\section{Pengumpulan data}

Data yang dikumpulkan terdiri dari data primer dan data sekunder. Data primer diperoleh dengan cara melakukan survei dan wawancara responden yang terkait dengan kegiatan tata niaga akar kuning yaitu para pedagang terkait. Data sekunder yaitu data yang diperoleh melalui pustaka, laporan tertulis dan dokumen-dokumen.

\section{Analisis Data}

Data yang diperoleh dianalisis secara kualitatif. Data yang dianalisis adalah hasil wawancara, pengamatan dan studi dokumen yang telah dituangkan dalam catatan lapangan (Pasolong, 2005).

\section{HASIL DAN PEMBAHASAN}

\section{Potensi Pasar dan Tata Niaga Akar Kuning}

Berdasarkan hasil pengamatan dan wawancara dengan pedagang obat tradisional di Pasar Martapura dan Rantau, mereka mendapatkan akar kuning dari pedagang perantara. Menurut para pedagang, mereka tidak banyak menjual akar kuning karena masyarakat sebagai konsumen sedikit sekali mengetahui bahwa akar kuning dapat dijadikan sebagai obat tradisional. Alasan lainnya adalah konsumen mempunyai tanaman obat lain yang mempunyai khasiat yang sama dengan akar kuning. Konsumen yang biasa membeli akar kuning umumnya adalah yang berkecimpung di bidang obat-obatan tradisional.

Rantai perdagangan yang terlibat dalam tata niaga akar kuning dapat kita lihat pada Gambar 1.

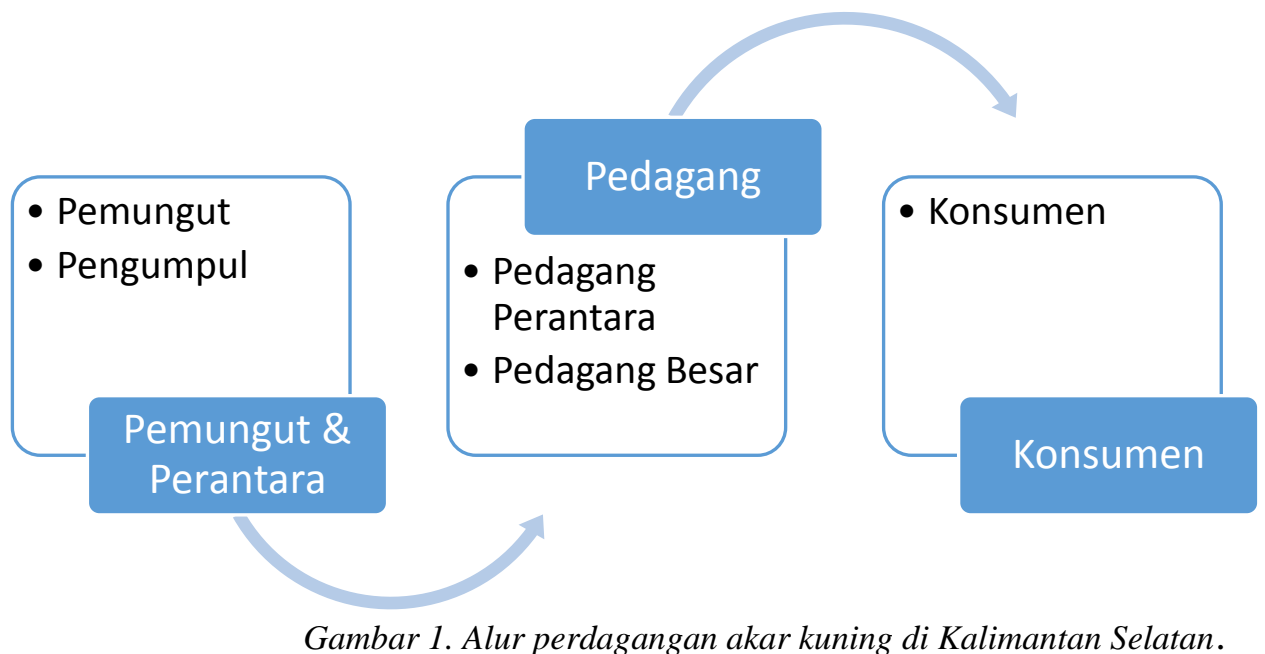

Pada tingkat pemungut, untuk mendapatkan akar kuning mereka hanya mencari jika ada kerabat atau diminta oleh pengumpul, dan apabila tidak ada permintaan maka mereka umumnya tidak mencari akar kuning. Mereka memahami jika akar kuning merupakan tanaman yang dapat diakses untuk dipungut dan dijual; kegiatan pemungutan akar kuning sebagai alternatif mata pencaharian; dan berdasarkan pengamatan hanya sekelompok kecil masyarakat yang 
memiliki pengetahuan tentang tanaman akar kuning. Hal ini karena akar kuning masih belum dikenal secara luas oleh masyarakat untuk pengobatan tradisional.

Pengumpul dan pedagang perantara merupakan pedagang yang menghubungkan pemungut dengan pasar (pedagang besar dan konsumen), meskipun terkadang tidak selalu begitu, seperti yang terlihat pada gambar 1 . Ada pemungut dan pengumpul yang langsung menjual ke pedagang besar ataupun pedagang perantara yang langsung menjual ke konsumen tanpa melalui pedagang besar. Secara kemampuan akses informasi dan permodalan, pengumpul, pedagang perantara dan pedagang besar mempunyai akses informasi dan modal yang lebih baik daripada pemungut. Secara umum, pemungut, pengumpul, pedagang perantara dan pedagang besar mempunyai homogenitas dalam pemanfaatan akar kuning yang terwujud melalui interaksi dan proses kerja sama dengan membentuk pola ketergantungan tata niaga akar kuning. Hess dan Ostrom (2007) menyatakan bahwa komunitas yang homogen adalah apabila komunitas, baik penyedia maupun pengambil keputusan bersatu dalam pemanfaatan sumber daya bersama yang terwujud melalui proses kerja sama dan koordinasi dalam menentukan sumber daya bersama.

Tata niaga akar kuning menggambarkan peredaran akar kuning yang sudah sampai di pedagang. Para pedagang besar mendapatkan akar kuning dari pedagang perantara dan pengumpul mendapatkan akar kuning dari pemungut. Konsumen pada saluran tata niaga akar kuning dari pemungut adalah herbal ists dan industri jamu tradisional skala kecil.

Berdasarkan pengamatan di Pasar Martapura dan Rantau serta hasil wawancara dengan pedagang yang menjual akar kuning di tempat tersebut, prospek pasar akar kuning berada dalam kondisi biasa saja, namun belum bisa dikatakan memiliki prospek yang baik dan layak, mengingat kebutuhan industri jamu tradisional akan akar kuning tidak besar. Industri jamu tradisional membutuhkan akar kuning dalam jumlah kecil saja dan selama ini belum mengalami kesulitan dalam memperoleh bahan baku. Menurut para pedagang di Martapura kebutuhan akan akar kuning saat ini masih dikatakan cukup, tidak pernah mengalami kekurangan bahan baku.

Di luar negeri terutama di negara India dan Srilangka, akar kuning menjadi produk unggulan. Di Srilangka dan Propinsi Kerala di India, kebutuhan tahunan akar kuning jenis Coscinium fenestratum, untuk pengobatan tradisional sebesar 54 ton dan 143 ton (Tushar et al., 2008). Di negara bagian Kerala, India, pemasaran tanaman obat di bawah kendali pemerintah daerah dan dilarang untuk diekspor. (Preetha, Laladhas, \& Oommen, 2015)

Secara umum untuk pasar ekspor, tumbuhan obat dapat diekspor ke negara lain dengan pangsa pasar utama tumbuhan obat Indonesia yaitu Amerika Serikat, Jepang, Perancis, Jerman, Switzerland, dan Inggris (BiofarmakaIPB, 2002).

\section{Strategi Pengembangan Akar Kuning}

Untuk strategi pengembangan akar kuning, strategi yang dapat di ambil yaitu;

1. Kontinuitas ketersediaan akar kuning Meningkatnya jumlah industri obat tradisional di Indonesia dan tingginya penggunaan obat tradisional dan produk biofarmaka di dalam maupun di luar negeri mengakibatkan tingginya permintaan terhadap penyediaan bahan 
baku obat dari tumbuhan yang berkualitas secara kontinyu. Pemanenan yang melampaui batas kemampuan regenerasinya akan menyebabkan kelangkaan bahkan kepunahan spesies tersebut (Balittro, 2001).

Akar kuning dapat menjadi terancam punah karena metode pengumpulan yang tidak berkelanjutan di alam bebas. Untuk itu, pemerintah pusat atau daerah harus segera menyusun dan memiliki pedoman dalam memanen akar kuning, sehingga memungkinkan tanaman akar kuning untuk beregenerasi dari tahun ke tahun. Dengan cara ini, kelangsungan hidup tanaman akar kuning jangka panjang akan berlangsung. Sehingga pemungut akar kuning akan tetap memiliki sumber penghasilan dan Industri Jamu akan memiliki persediaan bahan baku akar kuning untuk jangka panjang.

Strategi pengembangan akar kuning melalui budidaya dapat dilakukan secara masif, baik secara in-situ maupun ex-situ. Hal ini mengingat bahwa ketersediaan lahan untuk budidaya tumbuhan obat di Indonesia masih cukup luas sehingga memungkinkan tumbuhan akar kuning di tanam dalam skala besar guna menjamin pasokan bahan baku obat secara kontinyu ke industri biofarmaka yang ada baik di dalam maupun di luar negeri.

\section{Standar mutu simplisia akar kuning}

Potensi akar kuning yang mengandung senyawa berberin tidak hanya berkhasiat dapat mengobati penyakit seperti diabetes saja, tetapi juga anti kanker, anti malaria (Raza et al., 2015; Sun et al., 2009). Namun, mutu simplisia akar kuning sangat bergantung dari beberapa faktor, mulai dari penanaman, pengumpulan, pengolahan bahan baku, proses produksi sampai dengan peredaran. Oleh karena itu, untuk memperoleh standar mutu yang baik harus mengacu pada;

- Materia Medika Indonesia

- Farmakope Herbal Indonesia, 2008

- Parameter Standar Umum Ekstrak Tumbuhan Obat, Departemen Kesehatan, 2000 (Keputusan Menteri Kesehatan R.I No: 55/MENKES/SK/I/2000

- Monografi Ekstrak Tumbuhan Obat Indonesia (METOI), Badan POM 2004

Beberapa acuan yang ada tersebut diharapkan akan dapat menjamin produk akhir baik berupa obat, ekstrak atau produk ekstrak yang tidak hanya memiliki mutu yang baik saja, tetapi juga bermanfaat serta aman bagi konsumen.

\section{KESIMPULAN DAN SARAN}

Di Kalimantan Selatan berdasarkan pengumpulan data di lapangan, kebutuhan akar kuning untuk industri jamu tradisional masih relatif sedikit dan ketersediaannya masih memadai untuk memenuhi kebutuhan di tingkat lokal. Hal ini mengindikasikan bahwa saat ini belum terjadi eksploitasi besar-besaran di alam untuk memenuhi kebutuhan pasar baik di pasar Martapura dan pasar tradisional Rantau, di Kalimantan Selatan. Namun, dalam rangka untuk menjamin ketersediaan akar kuning secara berkelanjutan ke depan pemerintah tidak hanya perlu mengatur pedoman dalam memanen akar kuning saja, tetapi juga upaya konservasi dan budidayanya baik secara ex-situ maupun in-situ. Selain itu, serangkaian kegiatan penelitian baik potensi dan penyebaran akar kuning juga sangat perlu dilakukan sebagai dasar untuk menentukan kuota pemungutan akar kuning secara lestari termasuk penelitian lanjutan untuk menjawab bagaimana kebutuhan akar 
kuning secara luas di seluruh wilayah Indonesia.

\section{UCAPAN TERIMA KASIH}

Penulis mengucapkan terima kasih kepada Mardi T. Rengku, Yusuf Wibisono dan rekan lain yang telah membantu dalam pengumpulan data di lapangan, Kepada bapak Ishak Yassir sebagai Proofreader. Penulis juga mengucapkan terima kasih kepada Pimpinan Balitek KSDA beserta staf yang telah membantu kelancaran administrasi penelitian. Penelitian ini dibiayai oleh DIPA Balitek KSDA tahun anggaran 2016

\section{DAFTAR PUSTAKA}

[1]. Ahmed, T., Gilani, A. U. H., Abdollahi, M., Daglia, M., Nabavi, S. F., \& Nabavi, S. M. (2015). Berberine and neurodegeneration: A review of literature. Pharmacological Reports, 67(5), 970-979. https://doi.org/10.1016/j.pharep.2015.03.002

[2]. Balittro. (2001). Pengembangan agribisnis berbasis tanaman obat. Prosiding Seminar Nasional XIX Tumbuhan Obat Indonesia. Bogor: Balai Penelitian Tanaman Rempah dan Obat Bogor bekerjasama dengan Kelompok Kerja Nasional Tumbuhan Obat Indonesia dan Pusat Penelitian dan Pengembangan Perkebunan.

[3]. Biofarmaka-IPB. (2002). Tanaman Obat Indonesia: Keragaan Pasar, Standar Mutu dan Permasalahannya. Bogor: Pusat Studi Biofarmaka-LP IPB bekerjasama dengan Direktorat THSAT, Dirjen B2HP Deptan.

[4]. El-Wahab, A. E. A., Ghareeb, D. A., Sarhan, E. E., Abu-Serie, M. M., \& Demellawy, M. A. El. (2013). In vitro biological assessment of berberis vulgaris and its active constituent, berberine: antioxidants, antiacetylcholinesterase, anti-diabetic and anticancer effects. BMC Complementary and Alternative Medicine, 13.

[5]. Hess, C., \& Ostrom, E. (2007). Retrieved from Workshop in Political Theory and Policy Analysis.
[6]. Hornok. L. (1992). General aspects of medicinal plants. In L. Hornok, J. Wiley, \& Chichester (Eds.), Cultivation and Processing of medicinal Plants (pp. 3-9). New York: John Wiley \& Sons.

[7]. Indartik. (2009). Potensi Pasar Pulai Sebagai Sumber Bahan Baku Industri Obat Herbal Stusi Kasus Jawa Barat dan Jawa Tengah. Jurnal Penelitian Sosial Dan Ekonomi Kehutanan, 2(2), 159-165.

[8]. Kanaya, I. A., \& Firdaus, M. (2009). Daya Saing dan Permintaan Ekspor Produk Biofarmaka Indonesia di Negara Tujuan Utama Periode 2003-2012. Jurnal Manajemen \& Agribisnis, 11(3), 183-198.

[9]. Pasolong, H. (2005). Metode Penelitian Administrasi, untuk Organisasi Profit dan Non Profit. Makasar: Lembaga Penerbitan UNHAS.

[10]. Pramono E. (2002). Perkembangan dan prospek industri obat tradisional Indonesia. Prosiding Seminar Nasional Tumbuhan Obat Indonesia. Surabaya: Fakultas Farmasi Universitas Surabaya.

[11]. Preetha, N., Laladhas, K., \& Oommen, O. V. (2015). Stratagem for Sustainable Utilization of Medicinal Plant Resources. In Procedings of TIM-Research Conference on Sustainability and Management Strategy.

[12]. Raza, A., Aslam, B., Naseer, M. U., Ali, A., Majeed, W., \& Hassan, S. U. (2015). Antitumor Activity of Berberine Against Breast Cancer: a Review. International Research Journal of Pharmacy, 6(2), 81-85. https://doi.org/10.7897/2230-8407.06219

[13]. Sangat, H., Zuhud, E. A. M., \& Damayanti, E. K. (1999). Kamus Penyakit dan Tumbuhan Obat Indonesia (Etnofitimedika 1). Jakarta: Yayasan Obor Indonesia.

[14]. Sun, Y., Xun, K., Wang, Y., \& Chen, X. (2009). A systematic review of the anticancer properties of berberine, a natural product from Chinese herbs. Anti-Cancer Drugs, 20(9), 757-69. https://doi.org/10.1097/CAD.0b013e328330 d95b

[15]. Tushar, K. V., George, S., Remashree, A. B., \& Balachandran, I. (2008). Coscinium fenestratum (Gaertn.) Colebr.-A Review on this Rare, Critically Endangered and HighlyTraded Medicinal Species. Journal of Plant Sciences, 3(2), 133-145. 